$1-2009$

\title{
Modeling Federal Funds Rates: A Comparison of Four Methodologies
}

Anastasios G. Malliaris

Loyola University Chicago, tmallia@luc.edu

Mary Malliaris

Loyola University Chicago

Follow this and additional works at: https://ecommons.luc.edu/business_facpubs

Part of the Business Commons

\section{Author Manuscript}

This is a pre-publication author manuscript of the final, published article.

\section{Recommended Citation}

Malliaris, Anastasios G. and Malliaris, Mary. Modeling Federal Funds Rates: A Comparison of Four Methodologies. Neural Computing and Applications, 18, 1: 37-44, 2009. Retrieved from Loyola eCommons, School of Business: Faculty Publications and Other Works, http://dx.doi.org/10.1007/ s00521-008-0198-y

This Article is brought to you for free and open access by the Faculty Publications and Other Works by Department at Loyola eCommons. It has been accepted for inclusion in School of Business: Faculty Publications and Other Works by an authorized administrator of Loyola eCommons. For more information, please contact ecommons@luc.edu.

\section{(c) $($ †) $\ominus$}

This work is licensed under a Creative Commons Attribution-Noncommercial-No Derivative Works 3.0 License. (c) Springer International Publishing AG 2009 
MODELING FEDERAL FUNDS RATES:

\title{
A COMPARISON OF FOUR METHODOLOGIES
}

\author{
A. G. MALLIARIS ${ }^{1}$ \\ Loyola University Chicago \\ MARY MALLIARIS \\ Loyola University Chicago
}

\begin{abstract}
The celebrated Taylor Rule methodology has established that the decisions made by the Federal Open Market Committee concerning possible changes in short term interest rates reflected in Fed Funds are influenced by deviations from a desired level of inflation and from potential output. The Taylor Rule determines the future interest rate and is one among several methodologies than can be used to predict future Federal Funds. In this study we use four competing methodologies that model the behavior of Fed Fund interest rates. These methodologies are: time series, Taylor, econometric and neural network. Using monthly data from 1958 to the end of 2005 we distinguish between sample and out-of-sample sets to train, evaluate, and compare the models' effectiveness. Our results indicate that the econometric modeling performs better than the other approaches when the data are divided into two sets of pre-Greenspan and Greenspan periods. However, when the data sample is divided into three groups of low, medium and high Federal Funds, the neural network approach does best.
\end{abstract}

Current Version: January 2007

JEL Classification: E47, E52, G10

Key words: Federal Funds, Modeling Interest Rates, Taylor Rule, Neural Networks 


\section{MODELING FEDERAL FUNDS RATES:}

\section{A COMPARISON OF METHODOLOGIES}

\section{Introduction}

The key instrument used by the Federal Reserve to implement its monetary policy is the short-term interest rate called the Federal Funds rate. Fed watchers carefully analyze the decisions made by the Fed in order to anticipate the Fed's future moves to increase, decrease or leave unchanged the Fed Funds. Numerous methodologies have been developed to both model and forecast Fed Funds. For an account of some of the methodologies that have been applied, see Guidolin and Timmermann (2005) and Svensson (2003).

The basic purpose of this paper is to evaluate the forecasting performance of monthly Federal Funds rates using several competing methodologies. Rather than considering every available method, we shall restrict ourselves to the following four approaches: (1) a time series model where Fed Funds rates are determined solely by past rates; (2) a Taylor model where Fed Funds are functions of past influential factors; (3) an econometric model where Fed Funds are functions of past rates as well as influential factors, and (4) a neural network model using the same input variables as the econometric model. A chart indicating the monthly path of the Fed funds rates from 1957 through 2005 is shown in Graph 1.

Graph 1. Monthly Federal Funds rates from 1957 through 2005

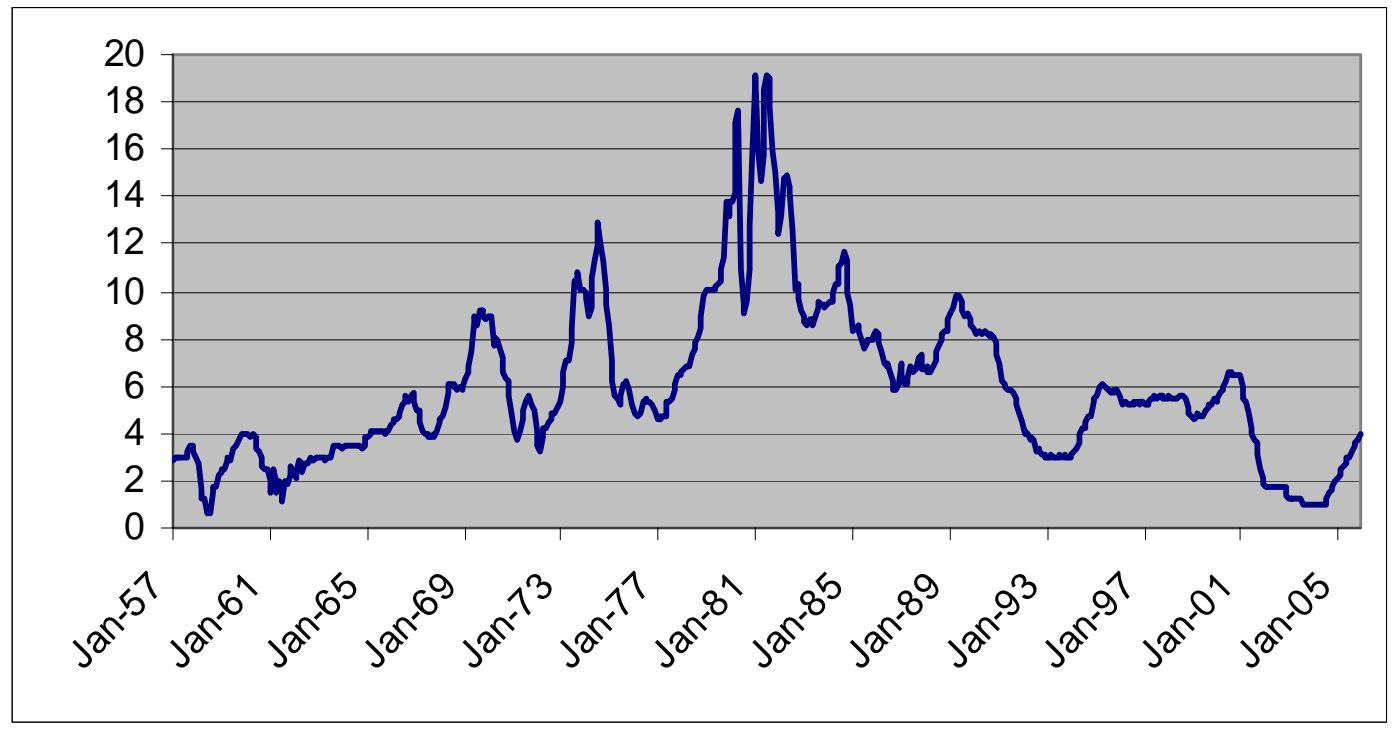




\section{Time Series Model: Fed Funds Are Determined Solely by Past Rates}

Much research has been conducted using a continuous-time short-term rate model specification such as

$$
d r=(\alpha+\beta r) d t+\sigma r^{\prime} d z
$$

where: $r=$ short-term interest rate

$\alpha, \beta, \gamma=$ model coefficients to be determined

$\sigma=$ standard deviation of the short-term rates

$z=$ Brownian motion

This formulation assumes that movements in interest rate are strictly a function of interest rate levels and volatility.

For investigations of such formulations, see Brenner, Harjes, and Kroner (1996). From (1) a discrete time series model can be obtained:

$$
r_{t}=\alpha+\beta r_{t-1}+\varepsilon_{t}
$$

where: $r_{t}=$ short-term interest rate at time $t$

$$
\begin{aligned}
& r_{t-I}=\text { short-term interest rate at time } t-1 \\
& \varepsilon_{t}=\text { model error term at time } \\
& \mathrm{E}\left(\varepsilon_{t}\right)=0 \\
& \alpha, \beta=\text { model coefficients to be determined }
\end{aligned}
$$

Depending on the date range evaluated, the value of $\beta$ is normally found to be very significant and close to 1 . This indicates that interest rates have high serial correlation. Such a result is to be expected since, on average, interest rates are only changed at most monthly by the Fed. In the sections that follow, the model described in (2) will be used as a base model on which to evaluate the effectiveness of other models. Graph 2 shows the relationship between fed funds at time $\mathrm{t}-1$ and time $\mathrm{t}$, sorted by funds at $\mathrm{t}-1$. Notice the close to linear relationship for all but the highest values on the graph.

\section{Graph 2. Fed funds at time $t-1$ vs. at time $t$}

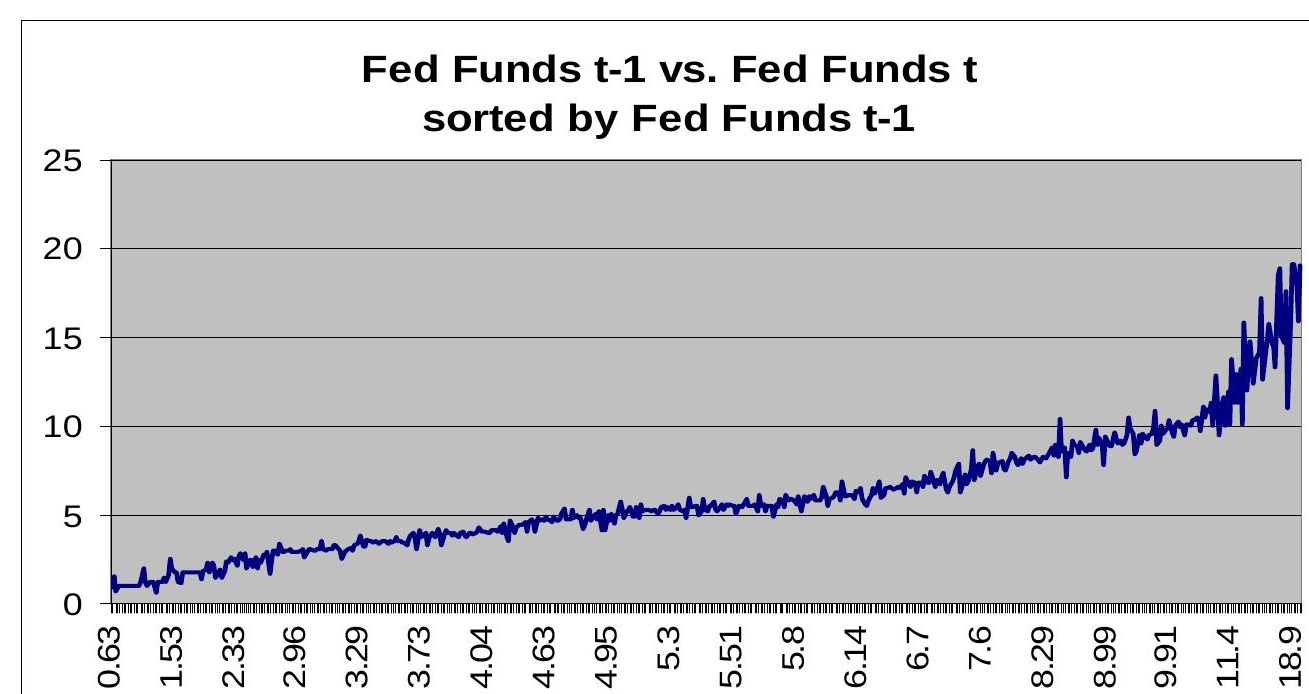




\section{The Taylor Model: Interest Rates Are Functions of Past Influential Factors}

The most famous Fed Funds model is the one proposal by Taylor (1993). It argues that Fed Funds are determined by the Fed's objectives to promote price stability and economic growth. There is both a quarterly and monthly version. We concentrate on the monthly version where:

$$
r_{t}=2+p_{t-1}+1 / 2\left(p_{t-1}-2\right)+1 / 2\left(u_{t-1}-4\right)
$$

where: $r_{t}=$ fed funds rate at $\mathrm{t}$

$p_{t-1}=$ lagged monthly inflation measured by CPI

$u_{t-1}=$ lagged monthly unemployment rate

By rearranging terms, this equation can also be written as:

$$
r_{t}=1+1.5 p_{t-1}+.5\left(u_{t-1}-4\right)
$$

There are multiple ways to get a measure of inflation. We compute the monthly rate of inflation and call it Inflation computed from the CPI using the following formula: $\mathrm{CPI}_{t+1}=\left(\mathrm{CPI}_{t+1}-\mathrm{CPI}_{t}\right) / \mathrm{CPI}_{t}$. Note that this second formulation of the equation indicates that the Federal funds rate should be changed 1.5 percent for each 1 percent change in inflation. It is felt that such a forceful reaction to inflation tends to drive future inflation to a lower value. Judd and Rudebusch (1998) show that when interest rates are not adjusted strongly in reaction to past inflation, the result can be rampant future inflation similar to the inflation exhibited during the era of $1970-1978$.

The Taylor rule has become the basis for comparison and development of other policy reaction functions. Modifications to the Taylor rule include the addition of other variables as exemplified by Clarida, Galí, Gertler (1998). Other considerations include the addition of expectations of future values of inflation and output, as shown in Orphanides (2001b). We used the Taylor rule in two formulations. In the first, values for the coefficients were taken as standard formulations as exhibited by equation 3'. In the second, we solved for the coefficients on the specific subsets of the data in order to see what the data-driven coefficients would be on each of these various data subsets. In the results, these two formulations of the Taylor equation are referred to as Taylor and Taylor2. Graphs 
3 and 4 show the paths of the Unemployment Rate and CPI Change.

Graph 3. Unemployment Rate

\section{Monthly Unemployment Rate 1957-2005}

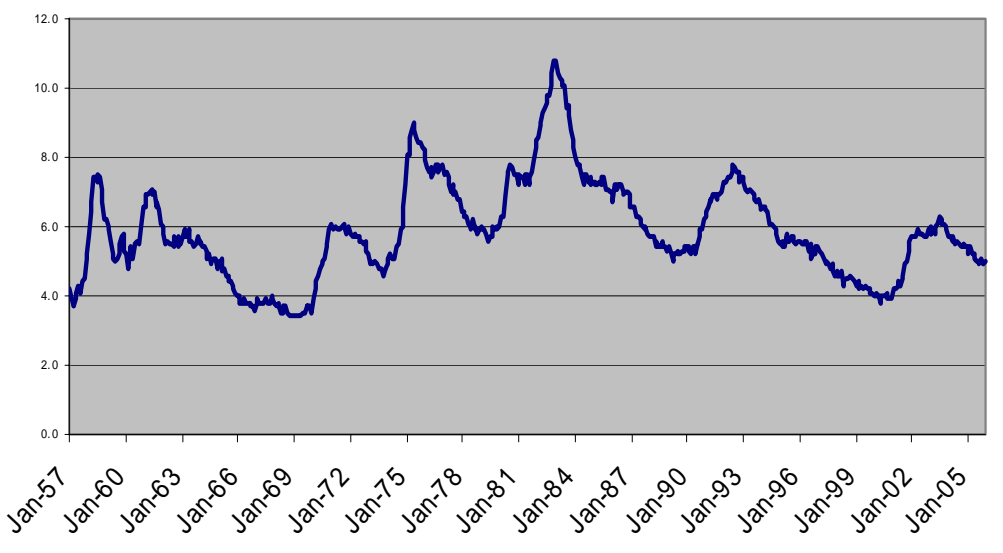

Graph 4. CPI Monthly Change Rate

CPI-All Items 12 month change rate Jan 1957-Nov 2005

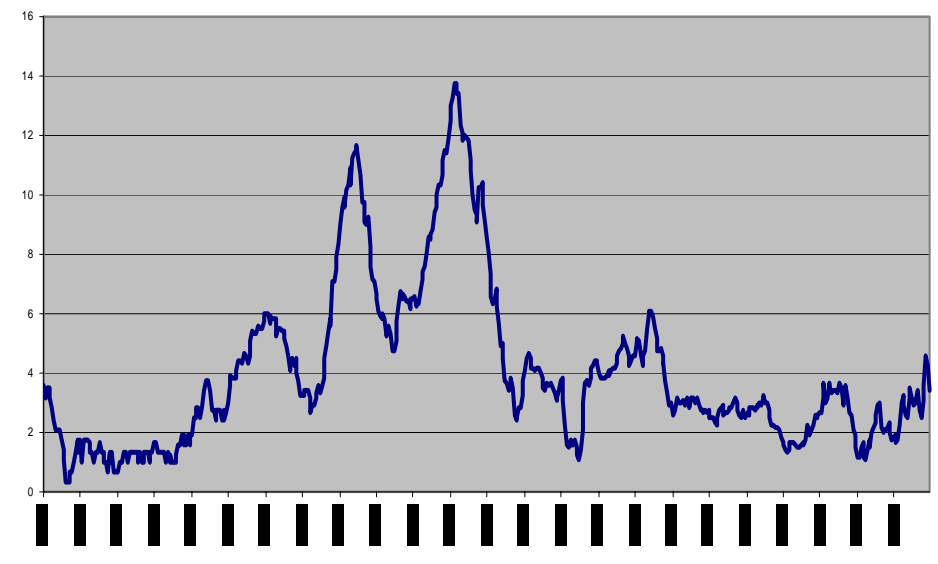




\section{The Econometric Model: Interest Rates Are Functions of Past Rates as Well as Influential Factors}

The third approach combines the two factors of the Taylor rule with previous interest rates, that is, with the time series model. By combining equations (2) and (3), we obtain the following using slightly different coefficient symbols:

$$
r_{t}=\alpha+\rho r_{t-1}+\beta\left(p_{t-1}-2\right)+\lambda\left(u_{t-1}-4\right)+\varepsilon_{t}
$$

where: $\mathrm{r}_{\mathrm{t}}=$ short-term interest rate at time $t$

$$
\begin{aligned}
& p_{t-1}=\text { inflation rate at time } t-1 \\
& u_{t-1}-4=\text { excess unemployment } \\
& \varepsilon_{t}=\text { model error term at time } t \text { where } \mathrm{E}\left(\varepsilon_{t}\right)=0 \\
& \alpha, \beta, \lambda, \rho=\text { model coefficients to be determined }
\end{aligned}
$$

Numerous investigators have evaluated equations of this form using past values of inflation and excess unemployment for various time intervals and various countries including Judd and Rudebusch (1998), and Clarida, Galí, and Gertler (1998). We observe that our econometric model is just a one equation model. Obviously, numerous multiple equation macroeconometric models have been developed, the most famous one being the Fed model. For a brief review of this model and its forecasting performance, see Tetlow and Ironside (2006). These authors document that when large macroeconometric models are built and used to assist in policy formulations the high degree of model uncertainty undermines the performance of such models.

\section{Interest Rates Can Be Determined by a Neural Network Using Past Rates and Influential Factors}

Neural networks have shown much promise in various financial applications, especially with complex problems (McNelis, 2005; Russell \& Norvig, 2003; Trippi \& Turban, 1996). A neural network is a non-linear estimator using weighted interconnected nodes to generate a forecast. It is very dependent upon the training data set since it adjusts its weights to optimize performance on this training data, but has the ability to often outperform linear models on complex data sets. The network contains three layers. The input layer has one node corresponding to each input variable. The output layer has one node corresponding to each desired output. In between these, the hidden layer is a set of nodes with no direct variable interpretation, but which serves to help mold the form of the inputs to the output. Each input and hidden layer node is multiplied by a weight that adjusts the importance of the node. A 
sigmoid function is applied to the weighted sum of each hidden layer and output layer node. In the hidden layer, this function of the weighted sum becomes the signal that is sent to the output node. In the output node, the function of the weighted sum is the forecast of the Fed funds rate. In this test, we will use the Fed Funds, CPI and Unemployment Rate as inputs to forecast the Fed Funds rate at the next time period. Graph 5 shows a general neural network architecture.

\section{Graph 5. Neural Network Architecture}

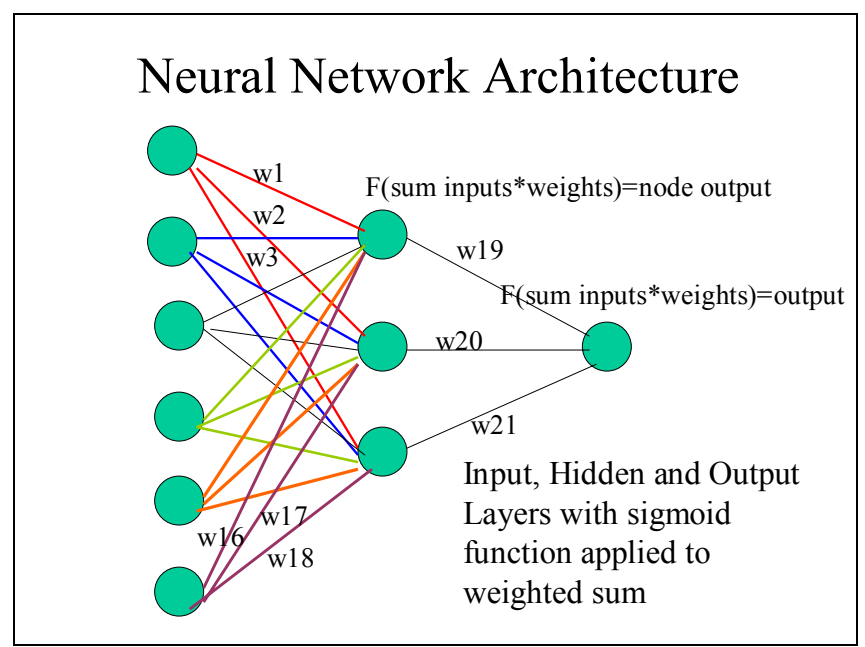

\section{Our Data}

We use monthly data for Fed Funds, inflation measured by the CPI and unemployment from January 1957 to December 2005. CPI data is annualized by calculating $\ln \left(\mathrm{x}_{\mathrm{t}} / \mathrm{x}_{\mathrm{t}-12}\right) * 100$ for each month. Percentages are adjusted to whole numbers, for example, $4 \%$ is used as 4 , not .04. The variable "Gap" was calculated as the Unemployment Rate minus 4. That is, it measures how far the Unemployment Rate varies from this critical value.

The computations for each model are performed for various subsamples of the set. These subsamples are divided first into two distinct time periods, then into three sets by value of the current Fed Funds rate. These five sets include: time prior to Greenspan (1957 through July 1987), since Greenspan (August 1987 through November 2005), the months where the adjusted Fed Funds rate was less than 5, between 5 and 10, and greater than 10. For each subsample, a random set of $10 \%$ of the rows was held out from training and used as the validation set. The models are all compared by looking at their performance on these five validation sets. Sizes of each of the model training and validation sets are shown in Table 1. The validation sets contain a wide range of data values and can be 
seen in graphs 6 and 7.

As explained in prior sections, not all variables are used in all models. The Random Walk model uses only the current Fed Funds number as an independent variable. The Taylor model uses CPI and Unemployment Rate. The Econometric and Neural Network models use current Fed Funds, CPI, and Unemployment Rate. The dependent variable for all models is Fed Funds for the next month.

\section{Graph 6. Validation Sets for Pre-Greenspan and Greenspan Data Sets}

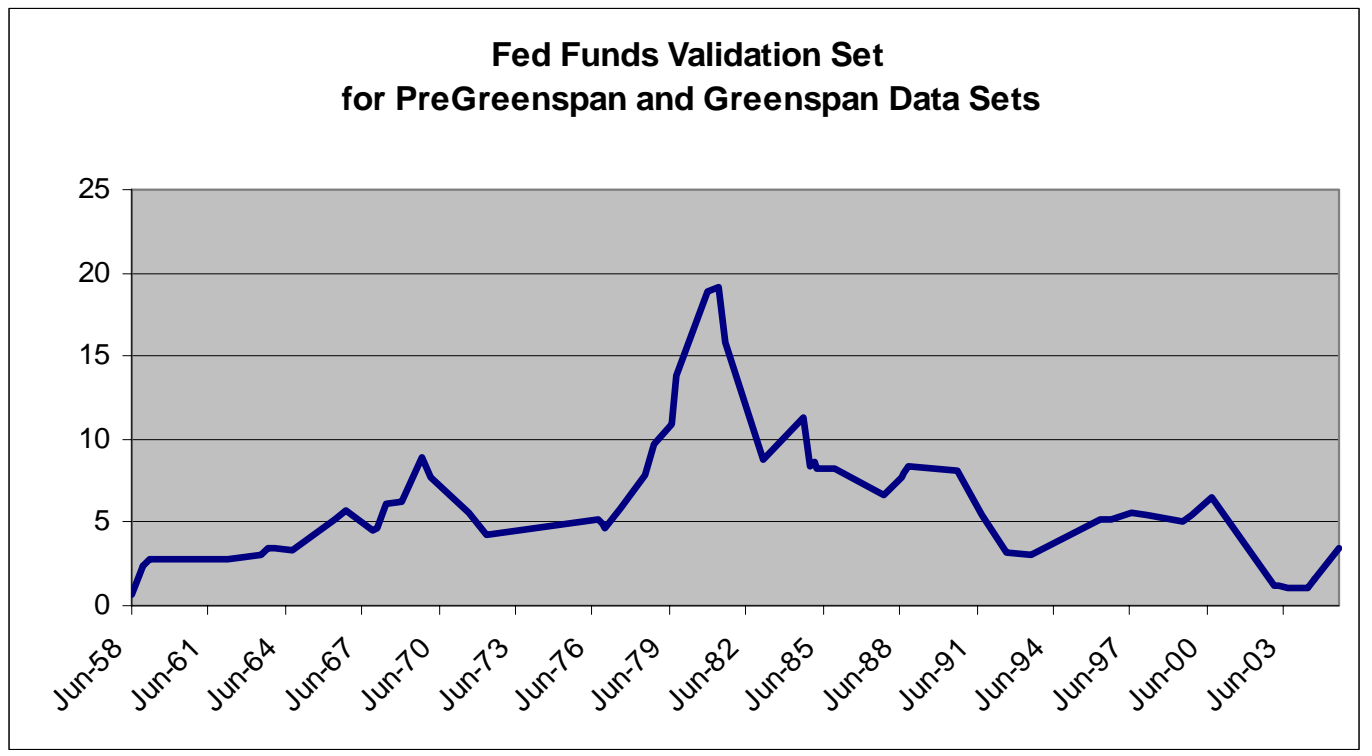

Graph 7. Validation Sets for Low, Medium, and High Data Sets

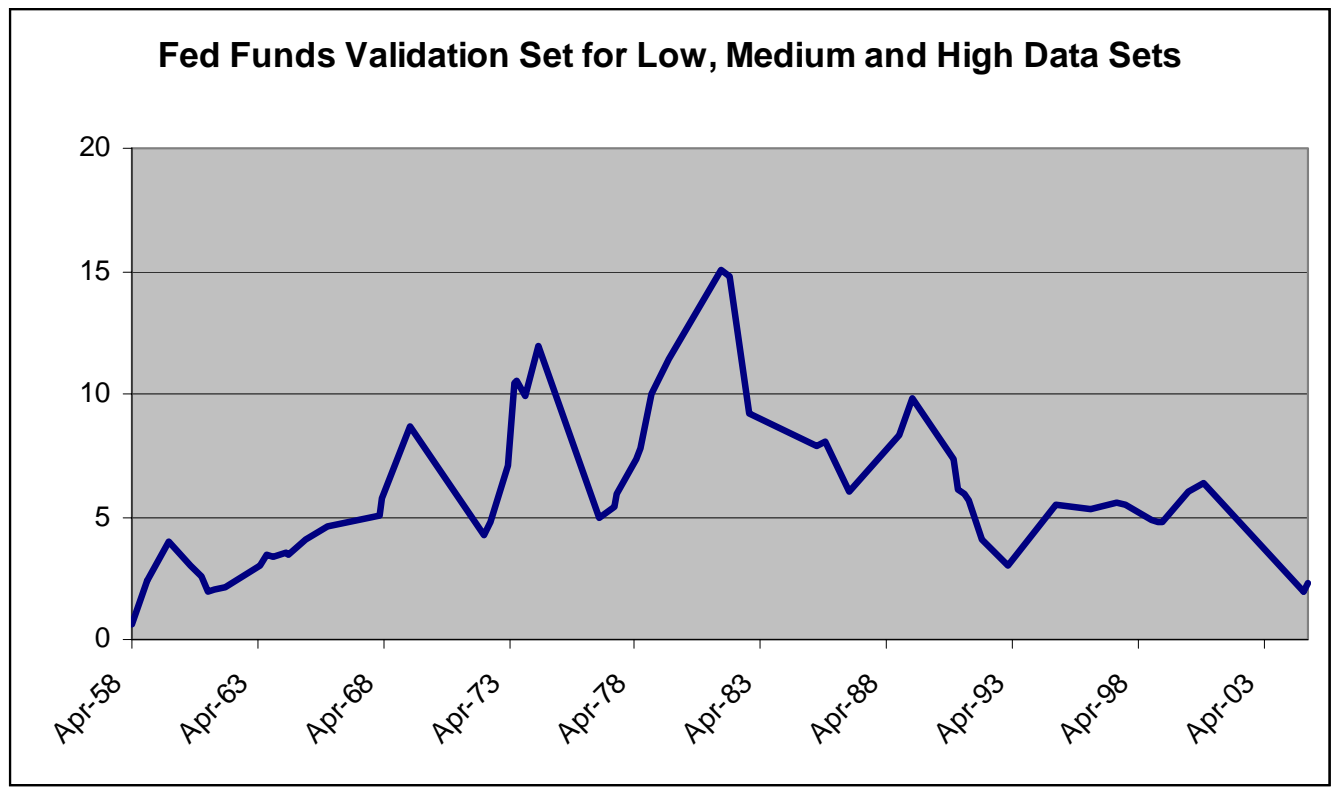


Table 1. Data Set Sizes

\begin{tabular}{|l||c|c|c|}
\hline Data Set & Training & Validation & Total \\
\hline Pre-Greenspan & 319 & 36 & 355 \\
\hline Greenspan & 197 & 22 & 219 \\
\hline $\mathrm{r}_{\mathrm{t}-1}: 0$ to 5 & 219 & 24 & 243 \\
\hline $\mathrm{r}_{\mathrm{t}-1}: 5.01$ to 10 & 243 & 27 & 270 \\
\hline $\mathrm{r}_{\mathrm{t}-1}:$ over 10 & 55 & 6 & 61 \\
\hline
\end{tabular}

\section{Model Results}

On the Random Walk model, Table 2 shows the model-generated values for the intercept and coefficient on each data set. On all but one set, the coefficient was almost 1, as expected. On the High set, it dropped to .879 and the intercept increased greatly.

Table 2. Random Walk equation values across data sets

\begin{tabular}{|l|c|c|c|c|c|}
\hline & Pre-Greenspan & Greenspan & High & Medium & Low \\
\hline Intercept & 0.177 & 0.006 & 1.48 & 0.021 & 0.02 \\
\hline Coefficient of $\mathrm{r}_{\mathrm{t}-1}$ & 0.973 & 0.995 & 0.88 & 0.995 & 1 \\
\hline
\end{tabular}

Table 3 shows the data-derived coefficients for the Taylor 2 equations. Only in the Greenspan data set does the CPI coefficient approach the 1.5 of the standard Taylor equation. The Gap coefficient is not close to $1 / 2$ in any data set and the intercept, rather than being equal to 1 , ranges from 1.8 to 5.8 .

Table 3. Taylor2 equation coefficients across data sets

\begin{tabular}{|l|l|l|l|}
\hline & Intercept & CPI & Gap \\
\hline PreGreenspan & 2.334 & 0.789 & 0.296 \\
\hline Greenspan & 1.797 & 1.477 & -0.935 \\
\hline High & 5.005 & 0.564 & 0.910 \\
\hline Medium & 5.755 & 0.197 & 0.161 \\
\hline Low & 2.837 & 0.496 & -0.490 \\
\hline
\end{tabular}


Table 4 shows only two consistencies from the expected model coefficients. The Fed Funds coefficient is near 1 in all cases, and the Gap coefficient is always negative and small, indicating a dampening effect of Gap. As Gap grows past 4, Fed Funds decrease. The intercept values range from .007 to 1.442 while the Adjusted CPI (that is, CPI - 2) is sometimes positive and sometimes negative.

Table 4. Values generated from the Econometric Model across data sets.

\begin{tabular}{|l|l|l|l|l|}
\hline & Intercept & Fed Funds & Adj. CPI & Gap \\
\hline PreGreenspan & 0.291 & 0.965 & 0.019 & -0.035 \\
\hline Greenspan & 0.047 & 0.994 & -0.007 & -0.024 \\
\hline High & 1.442 & 0.862 & 0.066 & -0.027 \\
\hline Medium & 0.007 & 1.002 & -0.003 & -0.019 \\
\hline Low & 0.125 & 0.983 & 0.018 & -0.022 \\
\hline
\end{tabular}

Table 5 reports the order of significance of the variables as used by the neural networks. Notice that, for times when the current rate is High, the variable significance shifts and Fed Funds becomes the least important of the variables.

Table 5. Order of variable significance in neural networks

\begin{tabular}{|l||l|l|l|l|l|}
\hline & PreGreenspan & Greenspan & Low & Medium & High \\
\hline Most Important & Fed Funds & Fed Funds & Fed Funds & Fed Funds & CPI \\
\hline & UnRate & CPI & CPI & CPI & UnRate \\
\hline Least Important & CPI & UnRate & UnRate & UnRate & Fed Funds \\
\hline
\end{tabular}

In all the models, we see that the splitting of data has given us significantly different equations. There is no one equation that will work equally well across all the data. However you decide to split the data, doing so will enable you to approximate the set better.

\section{Model Results on Validation Sets}

The mean squared error was calculated for each of the five models tested over each of the five subsets of data. The training and validation sets were distinct. Results show the lowest error amounts came from the models using all 
three of the variables for input. That is, in each subset of data, the lowest error came from either the Econometric or Neural Network model. More information enabled the models to approximate the target more effectively. The Random Walk model was very close to the lowest error in each subset, but never was the lowest. The two formulations of the Taylor model have significantly greater errors than any of the other three, over all data subsets. The results are shown in Table 6 with the lowest error in bold.

Table 6. Mean Squared Error Comparisons on Validation Sets

\begin{tabular}{|l|c|c||c|c|c|}
\hline Model / Data Set & PreGreenspan & Greenspan & Low & Medium & High \\
\hline Random Walk & 0.676 & 0.034 & 0.122 & 0.271 & 0.574 \\
\hline Taylor & 10.036 & 8.392 & 6.651 & 9.701 & 16.754 \\
\hline Taylor2 & 6.793 & 3.001 & 0.985 & 2.221 & 1.263 \\
\hline Econometric & $\mathbf{0 . 6 5 7}$ & $\mathbf{0 . 0 3 0}$ & 0.124 & $\mathbf{0 . 2 6 2}$ & 0.613 \\
\hline Neural Network & 1.121 & 0.129 & $\mathbf{0 . 1 0 4}$ & 0.269 & $\mathbf{0 . 3 7 2}$ \\
\hline
\end{tabular}

Notice, in the results from Table 6, we see that the Neural Network was not the best model when the data was split simply by time period. However, when the data was split by type based on current Fed Funds level, the Neural Network outperformed the Random Walk each time, and in 2 of the 3 sets, was best overall.

\section{Conclusions}

This paper has reviewed four methods for modeling the behavior of Federal funds. They are the standard random walk, the Taylor rule, an econometric model that relates the Federal funds to fundamental variables including past values of Federal funds and also the neural network approach. Using monthly data from 1958 to 2005 of several important macroeconomic variables, the results show that the econometric modeling performs better than the other approaches when the data are divided into two sets of pre-Greenspan and Greenspan. However, when the data sample is divided into three groups of low, medium and high Federal funds, the neural network approach does best. Actually, the neural network approach does best at the extreme sets of high and low interest rates, while the methodology based on econometric modeling performs best in the mid-range of interest rates. This is the range of interest rates between $5 \%$ and $10 \%$.

The main conclusion of our work is that separating the data set into more homogeneous segments makes it possible to improve the predictive ability of the equations. When the split is based on the current value of the Fed funds rate, 
then the neural network methodology outperforms both the random walk and Taylor approaches. When the split is simply time-based, then the econometric model is the one to use.

\section{Notes}

1. A.G. Malliaris holds the Mullady Chair and is Professor of Economics and Finance at Loyola University Chicago. He can be contacted at tmallia@luc.edu. Mary Malliaris is an Associate Professor of Information Systems at Loyola University Chicago. Her email address is mmallia@luc.edu. 


\section{Bibliography}

Brenner, Robin J., Richard H. Harjes, and Kenneth F. Kroner (1996). "Another Look at Models of the Short-Term Interest Rate.” Journal of Financial and Quantitative Analysis $31: 85-107$.

Clarida, Richard, Jordi Galí, and Mark Gertler (2000). "Monetary Policy Rules and Macroeconomic Stability: Evidence and Some Theory." Quarterly Journal of Economics 115: 147-180.

Guidolin, Massimo and Allan Timmermann (2005), "Forecasts of US Short-term Interest Rates: A Flexible Forecast Combination Approach”, Working paper 2005-059A, Federal Reserve Bank of St. Louis.

Judd, John P., and Glenn D. Rudebusch (1998). “Taylor's Rule and the Fed: 1970 - 1997.” Federal Reserve Bank of San Franscisco Economic Review 3 :3-16.

Kozicki, Sharon (1999), “How Useful Are Taylor Rules for Monetary Policy?”, Economic Review, Federal Reserve Bank of Kansas City, Second Quarter.

McNelis, Paul (2003). Neural Networks in Finance, Elsevier Academic Press.

Orphanides, Athanasios (2001a). "Monetary Policy Rules Based on Real-Time Data." American Economic Review 91, no. 4: $964-985$.

Orphanides, Athanasios (2001b). "Monetary Policy Rules, Macroeconomic Stability and Inflation: A View from the Trenches.” Working paper no. 115, European Central Bank, December: 1-43.

Russell, Stuart, and Peter Norvig (2003). Artificial Intelligence, A Modern Approach, $2^{\text {nd }}$ ed., Prentice Hall.

Svensson, Lars (2003), “What is Wrong with Taylor Rules? Using Judgment in Monetary Policy through Targeting Rules", Journal of Economic Literature, Vol 41, No 2.

Taylor, John B (1993), "Discretion versus Policy Rules in Practice.” Carnegie-Rochester Conference Series on Public Policy 39 : 195-214.

Taylor, John B. (1998), “An Historical Analysis of Monetary Policy Rules.” Working paper no. 6768, National Bureau of Economic Research October: 1-53.

Tetlow, Robert and Brian Ironside, (2006), "Real-Time Model Uncertainty in the United States: The Fed Model From 1996-2003”, European Central Bank Working paper Series, No. 610. 
Trippi, Robert, and Efraim Turban (1996). Neural Networks in Finance and Investing, Irwin Professional Publishing. 